\title{
Germanica
}

GERMANICA $\quad 60 \mid 2017$

Thomas Mann au tournant du siècle

\section{À propos de Theodor Lessing}

\section{Martine Benoit}

\section{OpenEdition}

Journals

Édition électronique

URL : http://journals.openedition.org/germanica/3835

DOI : ERREUR PDO dans /localdata/www-bin/Core/Core/Db/Db.class.php L.34 : SQLSTATE[HY000]

[2006] MySQL server has gone away

ISSN : 2107-0784

\section{Éditeur}

Université de Lille

\section{Édition imprimée}

Date de publication : 30 juin 2017

Pagination : 179-180

ISBN : 9782913857391

ISSN : 0984-2632

\section{Référence électronique}

Martine Benoit, «À propos de Theodor Lessing », Germanica [En ligne], 60 | 2017, mis en ligne le 30 juin 2019, consulté le 08 janvier 2021. URL : http://journals.openedition.org/germanica/3835 ; DOI :

https://doi.org/ERREUR PDO dans /localdata/www-bin/Core/Core/Db/Db.class.php L.34

SQLSTATE[HY000] [2006] MySQL server has gone away

(c) Tous droits réservés 


\section{Martine Benoit À propos de Theodor Lessing}

Intellectuel illustrant de manière exemplaire le destin tragique de la symbiose manquée entre Juifs et Allemands, Theodor Lessing reste un enfant malaimé de l'histoire. La postérité n'a voulu retenir de la vie de cet homme, journaliste, essayiste et professeur de philosophie, que deux événements, certes majeurs : le titre accrocheur de son dernier ouvrage, La haine de soi juive ; l'assassinat par des hommes de main des nazis le 30 août 1933 sur le sol tchécoslovaque, à Marienbad.

L'article de Jacques Darmaun revient quant à lui sur un épisode des années 1910. Theodor Lessing s'est installé en 1907 à Hanovre où il reste jusqu'au $1^{\text {er }}$ mars 1933 avant de s'enfuir à Marienbad. La vie à Hanovre est faite de tourments et de combats. Trois scandales ponctuent cette période : un scandale littéraire, qui voit donc Theodor Lessing aux prises avec l'écrivain Thomas Mann ; un scandale politico-juridique à l'occasion duquel Theodor Lessing s'érige en défenseur d'une République de Weimar sans cesse menacée ; un scandale universitaire enfin, qui illustre la montée du nationalisme et de l'antisémitisme dans le milieu estudiantin et dans la société allemande en général.

En 1910, Theodor Lessing écrit dans la revue théâtrale dirigée par Siegfried Jacobsohn, Die Schaubühne, une satire de Samuel Lublinski, alors critique littéraire célèbre. L'exemple de Samuel Lublinski lui sert d'illustration à la figure de l'Espritjude, un concept par lequel il désigne le littérateur juif assimilé, un écrivaillon snob et blasé qui réfléchit peu mais écrit beaucoup, le contre-exemple même du poète véritable. Une bataille littéraire éclate, on parle d'antisémitisme juif, Thomas Mann intervient violemment contre Theodor Lessing qu'il qualifie d' " exemple repoussant de mauvaise race juive » ${ }^{1}$. Pour comprendre la réaction si violente de Thomas Mann, qui commençait alors à être connu, il est bon de relever, comme le fait Jacques Darmaun, que Samuel Lublinski fut l'un des premiers critiques littéraires à accueillir favorablement son roman, Les Buddenbrook ou le déclin d'une famille (1901).

En 1924 éclate un deuxième scandale. Theodor Lessing a accepté de rendre compte pour le Prager Tagblatt, le quotidien des démocrates de langue alle-

1. - Article publié le 1er mars 1910 dans le Literarisches Echo, reproduit dans la brochure rédigée par Theodor Lessing pour rendre compte de l'animosité dont il était l'objet. Cf. Theodor Lessing, Samuel zieht die Bilanz und Tomi melkt die Moralkuh oder Zweier Könige Sturz - Eine Warnung für Deutsche, Satiren zu schreiben, Hannover, Verlag des „Antirüpels“, 1910, ici p. 32. 
mande en Tchécoslovaquie, d'un procès intenté à Fritz Haarmann : cet assassin dément avait commis entre vingt et soixante crimes, tuant de jeunes garçons après avoir abusé d'eux. Theodor Lessing tente de montrer la responsabilité de la police dans cette affaire : Haarmann étant un indicateur, les policiers auraient tardé à l'arrêter et se seraient ainsi rendu complices des crimes perpétrés. Theodor Lessing devient rapidement gênant, on lui retire sa carte de presse, ce qui lui ferme la porte de la salle d'audience. Il continue cependant à rédiger des articles, publie une brochure dans laquelle il fait une étude psychologique très approfondie du criminel ${ }^{2}$. Ce qui l'intéresse dans cette affaire, c'est le défi qui est lancé, il se veut défenseur de la République contre ses adversaires, en l'occurrence la police et cette pseudo-justice.

L'engagement républicain de Theodor Lessing déclenche peu après un scandale universitaire. Le 25 avril 1925 paraît dans le Prager Tagblatt un article de Theodor Lessing sur Hindenburg. On est à la veille du second tour des élections pour la présidence de la République, le Maréchal Paul von Hindenburg est le candidat du bloc des partis de droite. Theodor Lessing trace un portrait critique du héros de la Grande Guerre, fait rimer le mot « zéro » avec le nom de l'empereur romain, « Nero » en allemand :

Hindenburg n'est qu'un symbole représentatif, un point d'interrogation, un zéro. On peut certes dire : « Mieux vaut un zéro qu'un Néron ». Malheureusement l'histoire montre que derrière un zéro se cache toujours un Néron ${ }^{3}$.

Dès le 10 mai se crée un « comité de combat » au sein duquel étudiants et professeurs sont majoritaires et dont l'objectif est de chasser Theodor Lessing de l'École Polytechnique et même de la ville. De nombreux incidents ont lieu. Les étudiants nationalistes lancent des injures antisémites et empêchent Theodor Lessing de dispenser ses cours. Loin de le soutenir, la majorité de ses collègues se ligue contre lui et refuse de considérer l'attitude des étudiants comme une entrave à la liberté d'expression, ni même comme un appel à la haine antisémite. Theodor Lessing est finalement contraint de suspendre son enseignement à l'École Polytechnique et d'accepter un poste de chercheur.

En mars 1933, Theodor Lessing fuit l'Allemagne nazie pour Marienbad en Tchécoslovaquie où, le 30 août 1933, alors qu'il travaille à son bureau, il est assassiné par deux hommes de main des nazis.

2. - Brochure parue en 1925 sous le titre: Haarmann - Die Geschichte eines Werwolfs (Haarmann - L'histoire d'un loup-garou), rééditée sous la direction de Rainer Marwedel en 1989 au Luchterhand-Verlag (Haarmann sera finalement condamné à mort et exécuté).

3. - Theodor Lessing, « Hindenburg » (25.4.1925), article reproduit dans Rainer Marwedel (dir.), Theodor Lessing - „Ich warf eine Flaschenpost ins Eismeer der Geschichte“. Essays und Feuilletons (1923 - 1933), Darmstadt, Luchterhand, p. 69. 